\title{
Posaconazole loaded ocular inserts for antifungal activity
}

\author{
Kadir Aykaç ${ }^{1,2}$, Evrim Yenilmez ${ }^{2}$, Müzeyyen Demirel ${ }^{2}$, Ebru Başaran ${ }^{2 *}$ \\ ${ }^{1}$ Department of Pharmaceutical Technology, Faculty of Pharmacy, Erzincan Binali Yıldırım University, Erzincan, Turkey \\ ${ }^{2}$ Department of Pharmaceutical Technology, Faculty of Pharmacy, Anadolu University, Eskişehir, Turkey
}

\begin{tabular}{|c|c|}
\hline \multicolumn{2}{|c|}{ ARTICLE I N F O } \\
\hline \multicolumn{2}{|c|}{ Article history: } \\
\hline Received & 06 Mar 2020 \\
\hline Revised & 14 May 2020 \\
\hline Accepted & 18 May 2020 \\
\hline Online & 20 May 2020 \\
\hline Published & 15 Jun 2020 \\
\hline \multicolumn{2}{|l|}{ Keywords: } \\
\hline \multicolumn{2}{|c|}{ Chitosan } \\
\hline \multicolumn{2}{|c|}{ In vitro release } \\
\hline \multicolumn{2}{|c|}{ Ocular bioavailability } \\
\hline \multicolumn{2}{|c|}{ Ocular inserts } \\
\hline \multicolumn{2}{|c|}{ Posaconazole } \\
\hline $\begin{array}{l}\text { Corresponc } \\
\text { ebcengiz@ }\end{array}$ & $\begin{array}{l}\text { ng author: } \\
\text { nadolu.edu.tr }\end{array}$ \\
\hline
\end{tabular}

\begin{abstract}
A B S T R A C T
Corneal and conjunctival infections are common ocular diseases; however, sometimes lead to blindness when neglected. Despite most of the ocular drug delivery systems are in eye drop form, they suffer from poor retention on the ocular surface and low ocular bioavailability leading to unsatisfactory results even with repeated treatment. Therefore, there is a need for more effective drug delivery systems for the ocular application. The present study was carried out to demonstrate that ocular inserts effectively delivers a significant concentration of drug with topical administration for the treatment of fungal infections with the help of extended residence time on the ocular surface. Chitosan-based inserts were prepared by the freeze-drying method. The prepared inserts were evaluated for various parameters. Layered structures were revealed with scanning electron microscopy analyses. Thermal and structural behaviors were analyzed by differential scanning calorimetry and Fourier-transform infrared spectroscopy with nuclear magnetic resonance analyses, respectively. Drug contents were evaluated by a validated HPLC method. In vitro release studies were also performed in simulated tear fluid at $34 \pm 1^{\circ} \mathrm{C}$ for 48 hours. Analyses results revealed that chitosan-based ocular inserts were suitable systems for posaconazole delivery for the treatment of severe ocular fungal infections.
\end{abstract}

This is an open-access article licensed under the Creative Commons Attribution 4.0 International License (CC-BY). (cc) BY

\section{INTRODUCTION}

Ocular diseases require immediate treatment due to vision threatening critical clinical reasons [1]. Topical instillation is the most widely preferred non-invasive route of drug administration to treat diseases affecting mostly the anterior segment [2]. However, the treatment of ocular infections with traditional drug delivery systems (eye drop, etc.), especially with the topical application, is challenging due to the unique structural properties of the eye. The eye is segmented into two parts, anterior and posterior segments. The anterior segment of the eye comprises cornea, aqueous humour, iris, ciliary body, and lens, whereas the posterior segment includes retina and vitreous humour [3]. Cornea, which is regarded as the main penetration site, acts as a barrier for both hydrophilic and lipophilic drugs [4,5]. Treatment approaches differ considering the target sites of the eye; therefore, the main strategies for the enhancement of ocular bioavailability are the extension of residence time on the corneal surface and the enhancement of corneal permeability by penetration enhancers [6]. In our study, ocular inserts were formulated for the maintenance of extended duration on the ocular surface. Chitosan was used as a polymeric lattice for the structural integrity of the inserts [7]. Chitosan is a biodegradable and non-toxic biomaterial, which has excellent mucoadhesive strength and has been routinely explored for controlled drug delivery at various mucosal sites of the body [5-8]. Chitosan is a polycationic polymer due to the positively charged amino groups [9-11]. Considering the negative charge of mucin layers at mucosal membranes, cationic drug delivery systems electrostatically interact with mucosal surfaces, which results in increased bioavailability with topical application [12-16].

Posaconazole is a second-generation triazole group member like voriconazole, ravuconazole, isavuconazole, and albaconazole, has greater potency, and possesses increased activity against resistance and emerging pathogens [17]. Posaconazole has also been investigated in phase III studies and approved by the regulatory agencies for the treatment and prophylaxis of invasive fungal infections; therefore, posaconazole was selected as an active agent considering its broad-spectrum activity [18].

In this study, posaconazole loaded chitosan inserts were prepared by the lyophilization method. Besides the longer duration period of the ocular inserts, electrostatic attractions between the negatively charged ocular surface and chitosanbased cationic inserts will enhance the ocular bioavailability of the active agent. Sustained release of drugs from polymeric network gives the possibility to reduce dose and dosing frequency while maintaining the effective topical treatment of sight-threatening severe ocular fungal infections. 


\section{MATERIALS AND METHODS}

\subsection{Materials}

Posaconazole was gifted by Abdi İbrahim İlaç (İstanbul, Turkey). Chitosan (high molecular weighted; 310000$375000 \mathrm{Da}$ ) and Acetic acid (glacial, $\geq 99 \%$ ) were purchased from Sigma-Aldrich (Steinheim, Germany). Ethanol, methanol, and acetonitrile were the products of Merck (Darmstadt, Germany). All other chemicals were in analytical grade.

\subsection{Preparation of Ocular Inserts}

Ocular inserts were prepared by lyophilization method [19]. Briefly, chitosan was dissolved $(40 \mathrm{mg} / \mathrm{mL})$ in acetic acid solution $(2 \%, v / v)$, and posaconazole was dissolved in ethanol:acetonitrile $(5: 1)$ mixture. Formulations were prepared by mixing these solutions with different concentrations (Table 1) and stirred for $24 \mathrm{~h}$ for the evaporation of the organic solvents.

The solutions were stored at $-80 \pm 5^{\circ} \mathrm{C}$, and lyophilization (3L, $-86^{\circ} \mathrm{C}$, Operon Freeze Dryer, Gimpo-City, Korea) method was applied. A uniform film was achieved and cut into pieces and were stored in well-closed containers until being analyzed (Figure 1).

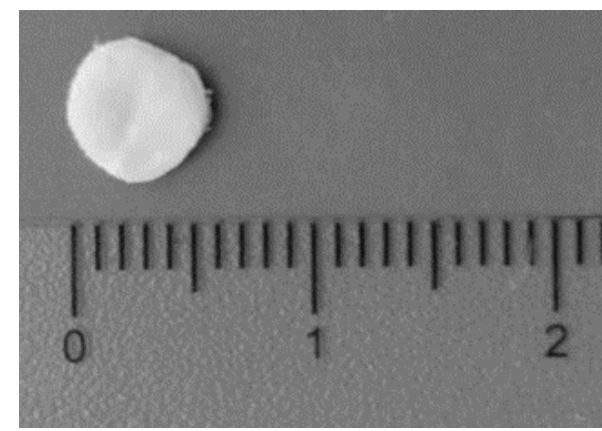

Figure 1. Ocular insert prepared by lyophilization method

\subsection{Characterization Studies of Ocular Inserts}

\subsubsection{Morphological analyses}

The morphological properties of posaconazole loaded inserts were investigated by scanning electron microscopy (SEM) analysis (Zeiss Ultra Plus Fesem, Germany).

\subsubsection{Differential scanning calorimetry analyses}

Structural and crystallinity changes of posaconazole and chitosan were evaluated using differential scanning calorimetry (DSC) (DSC-60, Shimadzu Scientific Instruments, Columbia, USA). Analyses were performed under nitrogen (flow rate of $50 \mathrm{~mL} / \mathrm{min}$ ) at $30-300^{\circ} \mathrm{C}$. Thermograms of pure posaconazole and polymer were used as references.

\subsubsection{Fourier transform infrared spectrophotometry analyses}

For the structural analyzes, Fourier transform infrared (FT-IR; IRAffinity-1S Shimadzu, Tokyo, Japan) analyses were performed. High-sensitivity DLATGS detector was used with Germanium-coated $\mathrm{KBr}$ Beam splitter at 7800 to $350 \mathrm{~cm}^{-1}$ wavenumber range. FT-IR spectra of pure posaconazole and chitosan were used as references.

\subsubsection{Nuclear magnetic resonance analyses}

For the evaluation of the interactions between the active agent and the polymer, ${ }^{1} \mathrm{H}-\mathrm{NMR}$ analyses were performed on Fourier 300 NMR (Brucker, Germany). Spectra of pure posaconazole and chitosan were used as references.

\subsubsection{Determination of posaconazole}

A modified high-performance liquid chromatography (HPLC) method was used for the determination of posaconazole [20]. Shimadzu 20 A (Tokyo, Japan) with Shimadzu Shim-Pack CLC-ODS column (Tokyo, Japan; column diameter: $4.6 \mathrm{~mm}$, column length: $25.0 \mathrm{~cm}$, particle diameter: $5 \mu \mathrm{m}$, and particle size: $100 \AA$ ) was used as the instrument. Acetonitrile:distilled water $(60: 40$, $\mathrm{v} / \mathrm{v}$ ) was used as the mobile phase with a flow rate of 1.0 $\mathrm{mL} / \mathrm{min} .20 \mu \mathrm{L}$ constant amount of samples were injected via an autosampler (SIL-20A, Shimadzu, Tokyo, Japan) and a photodiode array detector (SPD-M20A, Shimadzu, Tokyo, Japan) was used at $262 \mathrm{~nm}$. The column temperature was set to $25^{\circ} \mathrm{C}$. (CTO-10AS-VP, Shimadzu, Tokyo, Japan) Validation studies were performed for data reliability [21].

\subsubsection{In vitro drug release studies}

In vitro drug release studies were carried out by Apparatus 1 method with Pharma Test-PTWS820D (Hainburg, Germany) [22]. In this study, pH 7.4 simulated tear fluid (STF; $500 \mathrm{~mL}$ ) was used as the release medium at $34 \pm 1^{\circ} \mathrm{C}$ [23]. At predetermined time intervals $(0.25,0.5$, $0.75,1,1.5,2,3,6,9,24$, and 48 hours), $1 \mathrm{~mL}$ samples were taken from the release medium, and the equivalent volumes of fresh medium were added back for the maintenance of sink conditions. The amount of active substance in the samples was determined with HPLC. Each analysis was repeated three times.

\section{RESULTS AND DISCUSSION}

Compositions of the formulations were given in Table 1. Formulations were kept in well-closed containers until being analyzed.

Table 1. Compositions of the formulations

\begin{tabular}{lccc}
\hline \multirow{2}{*}{ Ingredients } & \multicolumn{3}{c}{ Formulation Code } \\
\cline { 2 - 4 } & CPS0 & CPS1 & CPS2 \\
\hline Chitosan HMW (mg) & 40.0 & 40.0 & 40.0 \\
Posaconazole (mg) & - & 16.7 & 25.0 \\
Ethanol:acetonitrile (5:1 (mL) & - & 2.0 & 3.0 \\
Acetic acid (2\%) (mL) & 9.6 & 9.6 & 9.6 \\
\hline
\end{tabular}

\subsection{Characterization Studies of Ocular Inserts}

Morphological and structural analyses were performed for the characterization of inserts.

\subsubsection{Morphological analyses}

SEM is regarded as a reference method for the determination dimensional properties of the samples [24], therefore in this study, morphological analyses of the inserts were determined by SEM analyses, and micrographs were presented in Figure 2. 


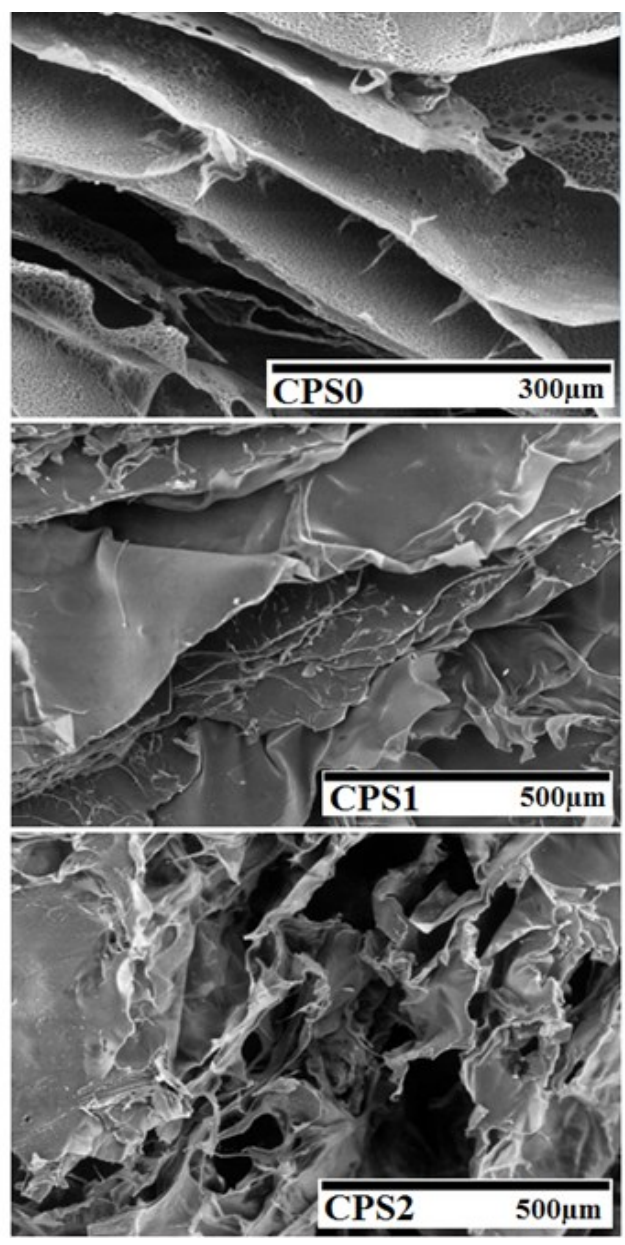

Figure 2. SEM micrographs of the formulations

Analyses results revealed that the inserts were formed in layers, which gives the possibility to enhance the tear sorption capacity of the formulations [25].

\subsubsection{Differential scanning calorimetry analyses}

DSC gives details about the thermal properties of the polymers, which is one of the most essential data for the processing of materials and also predicting the shelf life of the final product [26].

DSC thermogram of posaconazole exhibited a sharp endothermic peak at $174.59^{\circ} \mathrm{C}$. Also, the melting peak was revealed in the thermogram of the physical mixture of posaconazole and chitosan, showing no chemical interaction was revealed between the active agent and polymer (Figure 3). No peaks were revealed in the thermograms of chitosan, showing that the amorphous structure of the polymer while the posaconazole peak was disappeared in the thermograms of formulations showing that active agent was molecularly dispersed within the polymeric layers [27]. And also, water forms intermolecular hydrogen bonding with various chitosan and posaconazole's amine and hydroxyl groups, which helps in molecular rearrangement resulting in ease of chain mobility as well as crystallinity (Figure 3) [25].

\subsubsection{Fourier transform infrared spectrophotometry analyses}

FT-IR spectroscopy was used to investigate the interactions between posaconazole and chitosan (Figure 4).

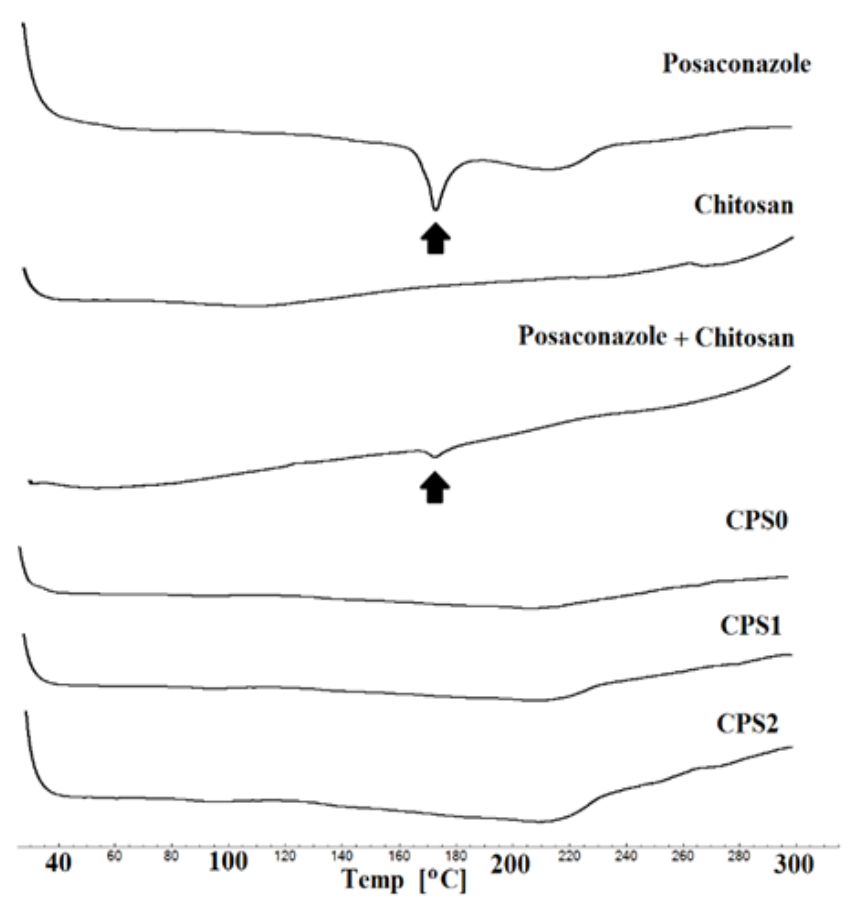

Figure 3. DSC thermograms of the pure materials, physical mixture, and formulations

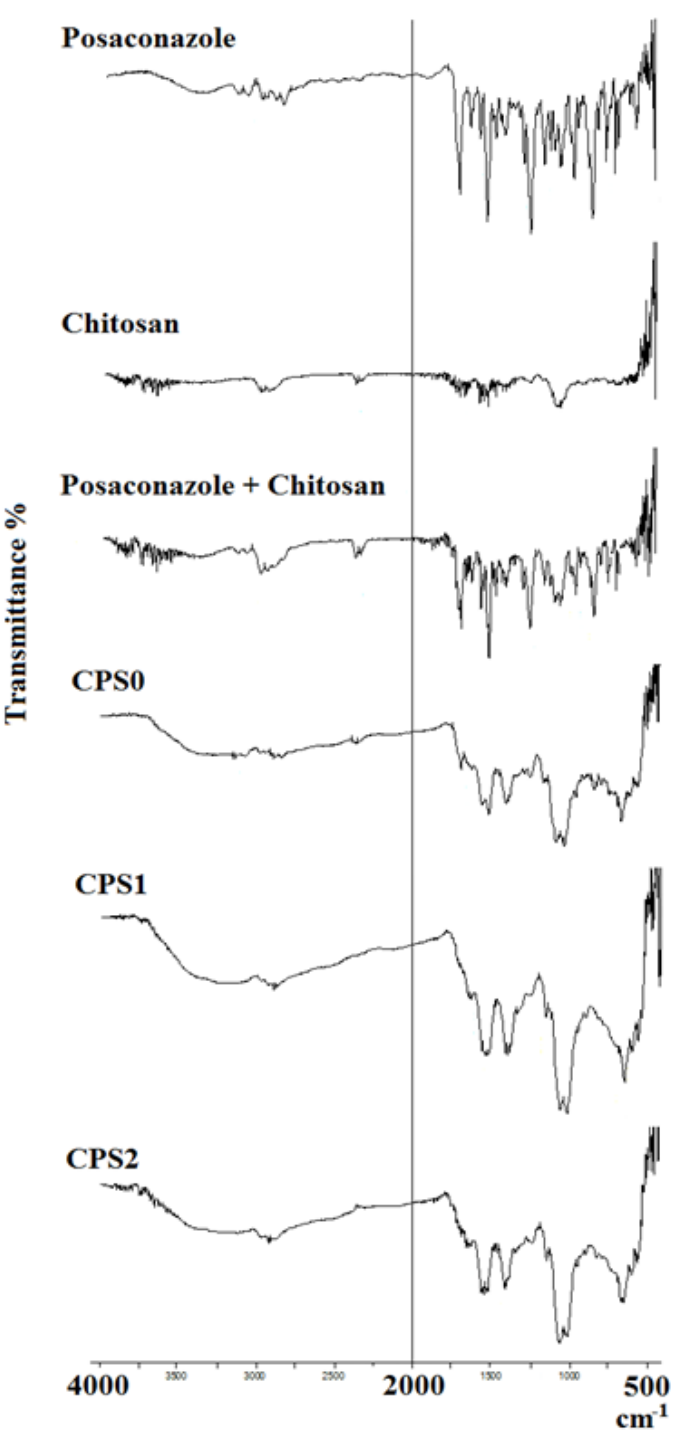

Figure 4. FT-IR spectra of the pure materials, physical mixture, and formulations 
FT-IR spectrum of posaconazole shows high-intensity absorption peaks at 3061, 2966, 1685, 1508, and $1224 \mathrm{~cm}^{-1}$ corresponding to the stretching vibrations of $\mathrm{OH}, \mathrm{CH}_{2}, \mathrm{C}=\mathrm{O}$, $\mathrm{C}=\mathrm{N}$, and $\mathrm{C}-\mathrm{N}$, respectively. The spectra of the physical mixtures corresponded to the spectra of individual components. Characteristic absorption peaks of posaconazole were revealed in the spectrum, indicating that posaconazole remained in the physical mixture without any interactions with chitosan [28]. However, characteristic signals of posaconazole could not be detected in the spectra of the formulations showing that active agent was molecularly dispersed within the polymeric layers in correlation with DSC analyses (Figure 3) [27,28].

\subsubsection{Nuclear magnetic resonance analyses}

For the evaluation of the interactions between the active agent and the polymer ${ }^{1} \mathrm{H}-\mathrm{NMR}$ analyses were performed, and analyses results were presented in Figure 5. Analyses results revealed that posaconazole signals were detected in the spectra of formulations with increased intensity (marked with arrows) in the range of 1-4 ppm showing that presence of posaconazole within the polymeric network without any chemical interaction [23,29].

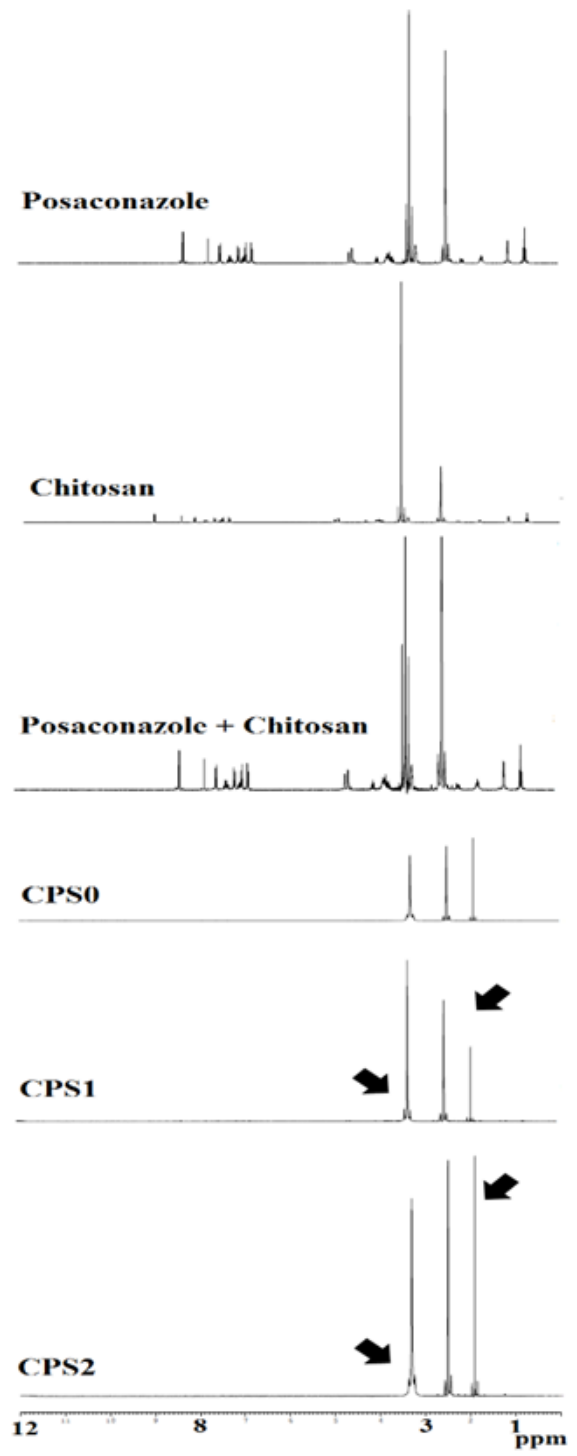

Figure 5. ${ }^{1} H$-NMR spectra of the pure materials, physical mixture, and formulations

\subsubsection{Determination of posaconazole}

Validation studies of the HPLC method were carried out in accordance with the guidelines of $\mathrm{ICH}$ within the range of $5-200 \mu \mathrm{g} / \mathrm{mL}$ [21]. $\mathrm{R}^{2}$ was 0.9999 , accuracy values were in the range of $98.96-102.58 \%$, while RSD value was less than $2 \%$ as a result of precision studies. The selectivity of the method was analyzed in comparison with placebo formulation (CPS0) and with all the components of the study (Figure 6).

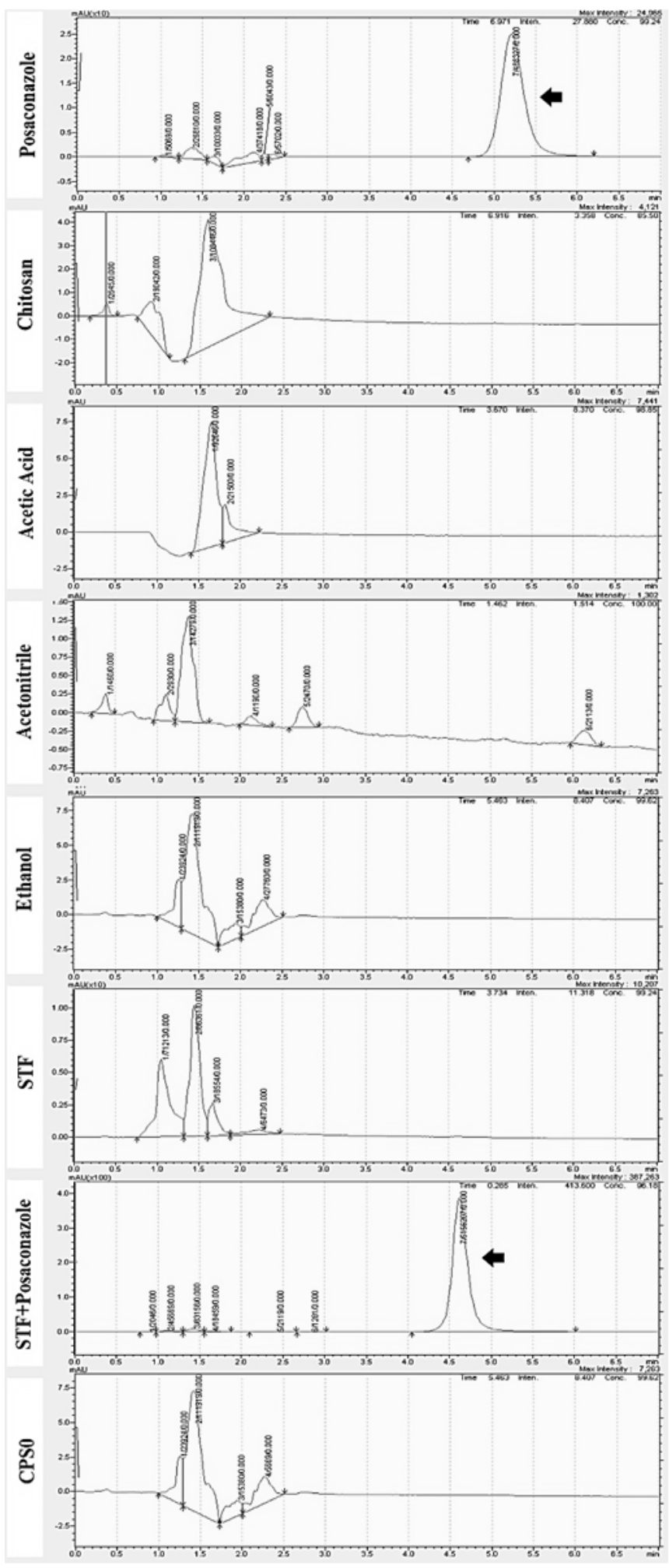

Figure 6. HPLC analyses signals of posaconazole in selectivity studies 
Analyses results revealed that no other substance did give signals at the point where the active substance was determined. For the evaluation of the posaconazole amount, a constant amount of formulation was dissolved in acetic acid $(2 \% ; \mathrm{v} / \mathrm{v})$ :ethanol:acetonitrile mixture $(1: 1: 1, \mathrm{v} / \mathrm{v})$ and were analyzed by HPLC. Analyses results revealed posaconazole amounts were $4.01 \pm 0.02 \%$ and $5.90 \pm 0.01 \%$ (mean $\pm \mathrm{SE} ; \mathrm{n}=3$ ) for the CPS1 and CPS2 formulations respectively (Table 1)

\subsubsection{In vitro release studies}

In vitro release studies were performed in $\mathrm{STF}$ at $\mathrm{pH} 7.4$ for 48 hours, and analyzes results were presented in Figure 7 $[23,29,30]$. According to the analysis results, the release rate of the active agent from CPS1 has reached the highest point of $40.40 \%$ while it was $49.09 \%$ for CPS2 after 48 hours. Despite the release rates could not reach $100 \%$, the analyses were conducted for 48 hours considering the residence time on the ocular surface.

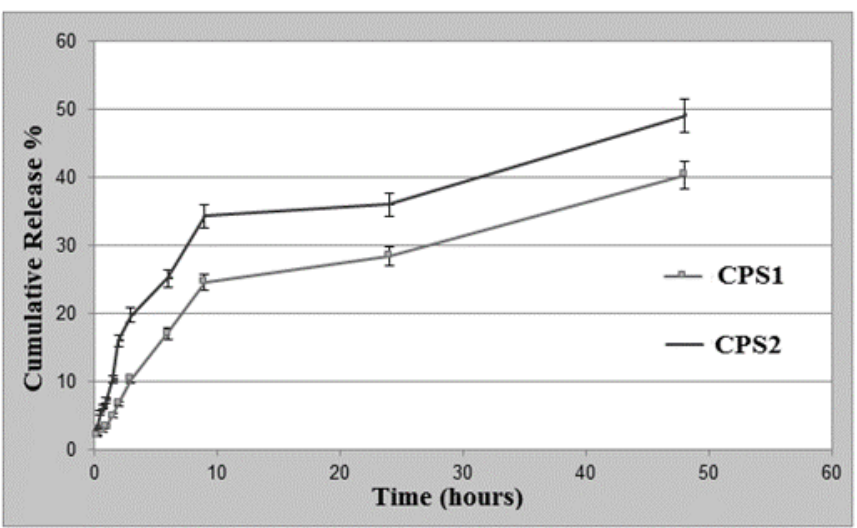

Figure 7. In vitro release profiles of formulations (mean $\pm S E ; n=3$ )

Posaconazole was practically insoluble in water $(0.012$ $\mathrm{mg} / \mathrm{mL}$ ); therefore, for the maintenance of sink conditions, in vitro release analyses were performed using Apparatus 1 (in $500 \mathrm{~mL} \mathrm{STF}$ at $34 \pm 1^{\circ} \mathrm{C}$ ) and release studies of the pure drug could not be performed with same method [23,29,31]. As the commercial products of posaconazole were in tablet, oral suspension, and injection forms, in in vitro release analyses comparison with commercial products could not be performed considering the results of the analyses will not contribute the ocular application of posaconazole via chitosan-based inserts [31].

Since most of the ocular formulations have poor performance due to their uncontrollable and undesirable burst releases with rapid removal from the ocular surface; biphasic release systems can maintain an initial burst release followed by a relatively steady release which enhances the ocular performance and ocular bioavailability of the applied formulation resulting ineffective treatment of severe ocular disorders [30,32].

\section{CONCLUSION}

The present study describes the development of posaconazole loaded chitosan inserts by the freeze-drying method. In vitro characterization analysis results revealed the characteristic properties of inserts in detail. SEM analyses revealed the layered structure of the system, which gives the possibility to increase the tear sorption of the system. Considering the cationic character of the polymeric structure enhanced ocular bioavailability with the help of electrostatic interactions between the oppositely charged ocular and polymeric surfaces as well as enhanced corneal duration period of the inserts.

\section{AUTHOR CONTRIBUTIONS}

Concept: EY, MD, EB; Design: EY, MD, EB; Supervision: MD, EB; Materials: EB; Data Collection and/or Processing: KA, EB; Analysis and/or Interpretation: KA, EB; Literature Search: KA, EB; Writing: MD, EB; Critical Reviews: EY, MD, EB.

\section{ACKNOWLEDGMENTS}

The study was financed by Anadolu University Scientific Research Project Foundation (BAP No: 1901S006). The authors would like to thank BIBAM management for SEM, and DOPNA-LAB for FT-IR and ${ }^{1} \mathrm{H}-\mathrm{NMR}$ analyses.

\section{CONFLICT OF INTEREST DECLARATION}

The authors declared no conflict of interest.

\section{REFERENCES}

[1] Chaudhari P, Ghate VM, Lewis SA. Supramolecular cyclodextrin complex: Diversity, safety, and applications in ocular therapeutics. Exp Eye Res. (2019); 189: 107829. https://doi.org/10.1016/j.exer.2019.107829

[2] Patel A, Cholkar K, Agrahari V, Mitra AK. Ocular drug delivery systems: An overview. World J Pharmacol. (2013); 2: 47-64. https://doi.org/10.5497/wjp.v2.i2.47

[3] Krishnaswami V, Kandasamy R, Alagarsamy S, Palanisamy R, Natesan S. Biological macromolecules for ophthalmic drug delivery to treat ocular diseases. Int J Biol Macromol. (2018); 110: 7-16. https://doi.org/10.1016/j.ijbiomac.2018.01.120

[4] Kalkancı A, Özdek Ş. Ocular fungal infections. Curr Eye Res. (2011) 36(3): 179-189. https://doi.org/10.3109/02713683.2010.533810

[5] Başaran E, Yenilmez E, Berkman MS, Büyükköroğlu G, Yazan Y. Chitosan nanoparticles for ocular delivery of cyclosporine A. $J$ Microencapsul. (2014); 31(1): 49-57.

https://doi.org/10.3109/02652048.2013.805839

[6] Başaran E, Yazan Y. Ocular application of chitosan. Expert Opin Drug Del. (2012); 9(6):701-712. https://doi.org/10.1517/17425247.2012.681775

[7] Franca JR, Foureaux G, Fuscaldi LL, Ribeiro TG, Castilho RO, Yoshid MI, Cardoso VN, Fernandes SOA, Cronemberger S, Nogueira JC, Ferreira AJ, Faraco AAG. Chitosan/hydroxyethyl cellulose inserts for sustained-release of dorzolamide for glaucoma treatment: In vitro and in vivo evaluation. Int J Pharm. (2019); 570: 118662. https://doi.org/10.1016/j.ijpharm.2019.118662

[8] Ludwig, A. The use of mucoadhesive polymers in ocular drug delivery. Adv Drug Deliv Rev. (2005); 57: 1595-1639. https://doi.org/10.1016/j.addr.2005.07.005

[9] Muxika A, Etxabide A, Uranga J, Guerrero P, de la Caba K. Chitosan as a bioactive polymer: Processing, properties and applications. Int $J$ Biol Macromol. (2017); 105: 1358-1368. https://doi.org/10.1016/j.ijbiomac.2017.07.087

[10] Kalantari K, Afifi AM, Jahangirian H, Webster TJ. Biomedical applications of chitosan electrospun nanofibers as a green polymer. Carbohyd Polym. (2019); 207: 588-600. https://doi.org/10.1016/j.carbpol.2018.12.011

[11] Dash M, Chiellini F, Ottenbrite RM, Chiellini E. Chitosan-A versatile semi-synthetic polymer in biomedical applications. Prog Polym Sci. (2011); 36: 981-1014. https://doi.org/10.1016/j.progpolymsci.2011.02.001

[12] De Campos, AM, Sánchez A, Alonso MJ. Chitosan nanoparticles: A new vehicle for the improvement of the delivery of drugs to the ocular surface. Application to cyclosporin A. Int J Pharm. (2001); 224: 159168. https://doi.org/10.1016/S0378-5173(01)00760-8

[13] Başaran E, Demirel M, Sırmagül B, Yazan Y. Cyclosporine-A incorporated cationic solid lipid nanoparticles for ocular delivery. $J$ Microencapsul. (2010); 27(1): 37-47.

https://doi.org/10.3109/02652040902846883 
[14] Alonso MH, Sanchez A. The potential of chitosan in ocular drug delivery. J Pharm Pharmacol. (2003); 55: 1451-1463 https://doi.org/10.1211/0022357022476

[15] Luo Q, Zhao J, Zhang X, et al. Nanostructured lipid carrier (NLC) coated with Chitosan Oligosaccharides and its potential use in ocular drug delivery system. Int J Pharm. (2011); 403: 185-191. https://doi.org/10.1016/j.ijpharm.2010.10.013

[16] Mahmoud AA, El-Feky GS, Kamel R, Awad GEA. Chitosan/ sulfobutylether- cyclodextrin nanoparticles as a potential approach for ocular drug delivery. Int J Pharm. (2011); 413: 229-236. https://doi.org/10.1016/j.ijpharm.2011.04.031

[17] Girmenia, C. New generation azole antifungals in clinical investigation. Expert Opin Investig Drugs. (2009); 18(9): 1279-1295. https://doi.org/10.1517/13543780903176407

[18] Ping B, Zhu Y, Gao Y, Yue C, Wu B. Second- versus firstgeneration azoles for antifungal prophylaxis in hematology patients: A systematic review and meta-analysis. Ann Hematol. (2013); 92: 831-839. https://doi.org/10.1007/s00277-013-1693-5

[19] Berretta J, Bumgardner, JD, Jennings JA. Lyophilized chitosan sponges. In: Amber Jennings J, Bumgardner JD, editors. Chitosan Based Biomaterials Volume 1. Cambridge:Woodhead Publishing; (2017). p. 239-253. ISBN 978-0-08-100230-8 https://doi.org/10.1016/B978-0-08-100230-8.00010-8

[20] Cendejas-Bueno E, Forastiero A, Rodriguez-Tudela JL, CuencaEstrella M, Gomez-Lopez A. HPLC/UV or bioassay: two valid methods for Posaconazole quantification in human serum samples. Clin Microbiol Infec. (2012); 18(12): 1229-1235. https://doi.org/10.1111/j.1469-0691.2011.03732.x

[21] International Conference on Harmonization (ICH). Guidance for industry: Q2B validation of analytical procedures: methodology. In Brussels, Belgium: International Conference on Harmonisation. 1996.

[22] USP 34 - Dissolution (2011). Retrieved (April 15, 2020) from https:// www.usp.org/sites/default/files/usp/document/harmonization/genmethod/stage 6 monograph 25 feb 2011.pdf
[23] Başaran E, Karaca Gençer H, Yenilmez E, Güven UM Voriconazole incorporated polymeric nanoparticles for ocular application. Lat Am J Pharm. (2017); 36(10): 1983-1994.

[24] Crouzier L, Delvallee A, Ducourtieux S, Devoille L, Tromas C, Feltin N. A new method for measuring nanoparticle diameter from a set of SEM images using a remarkable point. Ultramicroscopy. (2019); 207 112847. https://doi.org/10.1016/j.ultramic.2019.112847

[25] Jaber N, Aiedeh K. Sorption behavior and release kinetics of iron (II) ions by oleoyl chitosan polymeric nanoparticles. J Drug Deliv $S c i$ Tec. (2019); 54: 101354 https://doi.org/10.1016/j.jddst.2019.101354

[26] Sur S, Rathore A, Dave V, Reddy KR, Chouhan RS, Sadhu V. Recent developments in functionalized polymer nanoparticles for efficient drug delivery system. Nano-Structures \& Nano-Objects. (2019); 20: 100397. https://doi.org/10.1016/j.nanoso.2019.100397

[27] Başaran E, Şenel B, Yurtdaş Kırımlığlu, G, Güven UM, Yazan Y. Ornidazole incorporated chitosan nanoparticles for ocular application. Lat Am J Pharm. (2015); 34(6): 1180-1188.

[28] Tang P, Wang L, Ma X, Xu K, Xiong X, Liao X, Li H. Characterization and in vitro evaluation of the complexes of posaconazole with $\beta$ - and 2,6-di-o-methyl- $\beta$-cyclodextrin. AAPS Pharm Sci Tech. (2017); 18(1): 104-114. https://doi.org/10.1208/s12249-016-0497-z

[29] Başaran E, Ocular application of dirithromycin incorporated polymeric nanoparticles: An in vitro evaluation. Turk J Pharm Sci. (2017); 14(2): 191-200. https://doi.org/10.4274/tjps.69855

[30] Rathod LV, Kapadia R, Sawant KK. A novel nanoparticle impregnated ocular insert for enhanced bioavailability to posterior segment of eye: In vitro, in vivo and stability studies. Mat Sci Eng C. (2017); 71: 529-540. https://doi.org/10.1016/j.msec.2016.10.017

[31] Posaconazole. Retrieved (April 15, 2020) from https://www.drugbank.ca/drugs/DB01263

[32] Lee H, Xu G, Kharaghani D, Nishino M, Song KH, Lee JS, Kim IS. Electrospun tri-layered zein/PVP-GO/zein nanofiber mats for providing biphasic drug release profiles. Int J Pharm. (2017); 531: 101-107. https://doi.org/10.1016/j.ijpharm.2017.08.081 